University of Wollongong

Research Online

Australian Institute for Innovative Materials -

Papers

Australian Institute for Innovative Materials

2012

\title{
Polypyrrole coated nylon lycra fabric as stretchable electrode for supercapacitor applications
}

Binbin Yue

University of Wollongong

Caiyun Wang

University of Wollongong, caiyun@uow.edu.au

Xin Ding

Donghua University, China

Gordon G. Wallace

University of Wollongong, gwallace@uow.edu.au

Follow this and additional works at: https://ro.uow.edu.au/aiimpapers

Part of the Engineering Commons, and the Physical Sciences and Mathematics Commons

Research Online is the open access institutional repository for the University of Wollongong. For further information contact the UOW Library: research-pubs@uow.edu.au 


\title{
Polypyrrole coated nylon lycra fabric as stretchable electrode for supercapacitor applications
}

\author{
Abstract \\ Wearable electronics offer the combined advantages of both electronics and fabrics. Being an \\ indispensable part of these electronics, lightweight, stretchable and wearable power sources are strongly \\ demanded. Here we describe a daily-used nylon lycra fabric coated with polypyrrole as electrode for \\ stretchable supercapacitors. Polypyrrole was synthesized on the fabric via a simple chemical \\ polymerization process with ammonium persulfate (APS) as an oxidant and naphthalene-2,6-disulfonic \\ acid disodium salt ( $\mathrm{Na}_{2} \mathrm{NDS}$ ) as a dopant. This material was characterized with FESEM, FTIR, tensile \\ stress, and studied as a supercapacitor electrode in $1.0 \mathrm{M} \mathrm{NaCl}$. This conductive textile could endure \\ 1000 stretching cycles with $100 \%$ strain applied, and still retained its electrical conductivity and \\ electrochemical properties. Interestingly, we also found that this material showed improved \\ electrochemical properties when it was being stretched.

\section{Keywords} \\ supercapacitor, electrode, stretchable, applications, fabric, polypyrrole, lycra, nylon, coated

\section{Disciplines} \\ Engineering | Physical Sciences and Mathematics

\section{Publication Details} \\ Yue, B, Wang, C, Ding, X \& Wallace, GG (2012), Polypyrrole coated nylon lycra fabric as stretchable \\ electrode for supercapacitor applications, Electrochimica Acta, 68, pp. 18-24.
}




\section{Polypyrrole coated Nylon Lycra fabric as stretchable electrode for supercapacitor applications}

Binbin Yue, ${ }^{1,2}$ Caiyun Wang, ${ }^{1}$ Xin Ding ${ }^{2}$ and Gordon G. Wallace ${ }^{1, *}$

\footnotetext{
${ }^{1}$ ARC Centre of Excellence for Electromaterials Science,

Intelligent Polymer Research Institute,

AIIM Facility, Innovation Campus,

University of Wollongong, NSW 2522, Australia.

${ }^{2}$ College of Textiles, Donghua University, Shanghai 201620, China.
}

* Prof. G. G. Wallace, corresponding author.

Tel.: +612 4221 3127; fax: +61242213114.

E-mail address: gwallace@uow.edu.au (G.G. Wallace). 


\begin{abstract}
Wearable electronics offer the combined advantages of both electronics and fabrics. Being an indispensable part of these electronics, lightweight, stretchable and wearable power sources are strongly demanded. Here we describe a daily-used Nylon Lycra fabric coated with polypyrrole as electrode for stretchable supercapacitors. Polypyrrole was synthesized on the fabric via a simple chemical polymerization process with ammonium persulfate (APS) as oxidant and naphthalene-2, 6-disulfonic acid disodium salt $\left(\mathrm{Na}_{2} \mathrm{NDS}\right)$ as dopant. This material was characterized with FESEM, FTIR, tensile stress, and studied as a supercapacitor electrode in $1.0 \mathrm{M} \mathrm{NaCl}$. This conductive textile could endure 1000 stretching cycles with $100 \%$ strain applied, and still retained its electrical conductivity and electrochemical properties. Interestingly, we also found that this material showed improved electrochemical properties when it was being stretched.
\end{abstract}

KEYWORDS: Polypyrrole, e-textile, supercapacitors, stretchable electrode.

\title{
1. Introduction
}

The incorporation of electronics into wearable items has demonstrated significant advances in terms of miniaturisation, functionality and comfort. These e-textiles have found broad applications in continuous personal health monitoring, high performance sportswear, wearable displays and a new class of portable devices [1-5]. Being an indispensable part of these applications, lightweight, stretchable and wearable power sources including batteries and supercapacitors are strongly demanded. The ideal wearable power sources would be made into breathable textile formats with stretchability (i.e. mechanical resilience) being conformal to the curved surface and sustain its function during the body movement.

As one type of power sources, supercapacitors possess the advantages of higher power densities, excellent reversibility and long cycle life [6]. Recently, there has been an 
emerging interest in stretchable supercapacitors [7, 8]. Stretchable supercapacitor electrodes using single-walled carbon nanotubes (SWNT) integrated into poly (dimethylsiloxane) (PDMS) [7] or textile substrates [8] have been developed. Buckle-structured stretchable carbon nanotube macrofilms on PDMS exhibited a much similar specific capacitance with or without $30 \%$ strain applied ( $54 \mathrm{~F} \mathrm{~g}^{-1}$ to $52 \mathrm{~F} \mathrm{~g}^{-1}$ at a current density of $1 \mathrm{~A} \mathrm{~g}^{-1}$ ). The specific capacitances did not change, even up to 1000 charge-discharge cycles [7]. The stretchable textile-based supercapacitor was fabricated by integrating SWNT into fabric via a "dipping and drying" process [8]. It exhibited a specific capacitance of $62 \mathrm{~F} \mathrm{~g}^{-1}$ at a current density of $1 \mathrm{~mA} \mathrm{~cm}{ }^{-2}$, and no obvious capacitance fade was observed after being subjected to 100 elongation cycles with $120 \%$ strain applied.

Inherently conducting polymers (ICPs) is one important member of the supercapacitor materials family. However, to the best of the authors' knowledge, the application of ICPs coated fabric in stretchable supercapacitors has not been reported, though recently we have reported the stretchable buckle-structured polypyrrole integrated into a SIBS substrate for $\mathrm{Mg}$ batteries [9]. In particular, ICPs are interesting candidates for flexible energy storage devices due to their relatively high theoretical capacities, fast redox properties, lightweight and mechanical flexibility [10-14]. A flexible ultrafast all-polymer battery composed of PPy coated cellulose fibres electrodes could be charged with currents as high as $600 \mathrm{~mA} \mathrm{~cm}{ }^{-2}$ with only $6 \%$ capacity loss over 100 subsequent charge and discharge cycles [15]. Flexible supercapacitor with polypyrrole/manganese dioxide composites coated on polypropylene fibrous films as electrodes delivered an optimal capacitance of $\sim 110 \mathrm{~F} \mathrm{~g}^{-1}$ [16]. These two types of electrodes, PPy or PPy/ $\mathrm{MnO}_{2}$ coated fibre, were flexible but not stretchable at least in the reported structure. Moreover, ICPs are well-suited for the fabrication of conductive textiles [3, 17, 18], and ICPs coated textiles have been studied in energy storage [19-21]. 
Here we report a stretchable supercapacitor electrode material based on polypyrrole (PPy) coated Nylon Lycra fabric via chemical polymerization. We chose stretchable Nylon Lycra fabric as substrate due to its stretchability and wearing comfort. Although in our group $\mathrm{J}$. Wu et al. have reported some preliminary results about the resistance change of PPy coated Lycra fabric under strain of up to $60 \%$ [22], this resistance change during or after the elongation-relaxation cycles was not characterized. Also its electrochemical properties were not investigated. In this work, PPy coated Lycra fabric electrode demonstrated excellent stretchability. It could endure 1000 stretching cycles whilst retaining its electrical conductivity and electrochemical properties. Compared with the as-synthesized conductive fabric, the fabric after being subjected to 1000 stretching cycles with $100 \%$ strain applied delivered a nearly unchanged specific capacitance. In addition, the electrochemical performance was improved while this PPy coated fabric was being stretched.

\section{Experimental section}

\subsection{Reagents and materials}

Pyrrole, naphthalene-2, 6-disulfonic acid disodium salt ( $\left.\mathrm{Na}_{2} \mathrm{NDS}\right)$ and ammonium persulfate (APS) were obtained from Sigma-Aldrich. Pyrrole was freshly distilled, while all other chemicals were used as-supplied. All aqueous solutions were prepared with Milli-Q water $(\sim 18 \mathrm{M} \Omega)$. The textile used was a stretchable knitted fabric with $80 \%$ Nylon and $20 \%$ Lycra purchased from Spotlight Stores Pty Ltd.

\subsection{PPy polymerization on fabric}

Before polymerization, Nylon Lycra fabric was washed with an aqueous solution of scouring agent and sodium hydroxide for $1 \mathrm{~h}$ to remove grease and other impurities attached on them, followed by soaking and rinsing with $\mathrm{H}_{2} \mathrm{O}$ till neutral $\mathrm{pH}$. Deposition of pyrrole on textiles has been carried out by oxidation of pyrrole in the presence of textiles, following the 
method described in the previous reports [23, 24]. Briefly, the fabric samples $(2.08 \mathrm{~g})$ were immersed in APS and $\mathrm{Na}_{2} \mathrm{NDS}$ solution and kept at $4{ }^{\circ} \mathrm{C}$ for 30 minutes, followed by adding pyrrole solution dropwise to initiate polymerization. The polymerization reaction was performed at $4{ }^{\circ} \mathrm{C}$ for 2 hours. The coated fabrics were then washed with water and dried at ambient temperature. The concentration of monomer, oxidant and dopant was $0.02 \mathrm{M}, 0.02 \mathrm{M}$ and $0.009 \mathrm{M}$, respectively. The textile-liquor ratio was kept at 1:50 (w/v, g: ml). The amount of PPy deposited on the fabric was determined by the weight increase of the fabric after coating. The content of PPy in such composite was about $6.36 \%$.

\subsection{Characterization of PPy coated fabric}

The surface morphologies of the conductive fabric were investigated by means of a cold-field-gun field emission microscope (FESEM, JEOL JSM7500FA). FT-IR spectra were recorded on a FT-IR spectrometer (IRpretige-21, SHIMADZU) over the range from $800 \mathrm{~cm}^{-1}$ to $2000 \mathrm{~cm}^{-1}$. The surface resistance was determined according to the American Association of Textile Chemists and Colorists Test Method 76-1995. Two rectangular copper electrodes were placed on the fabric sample and the surface resistance (Rs) was given by:

$$
R_{s}(\Omega / \square)=\frac{W}{D} R^{*}
$$

Where, $\mathrm{R}^{\prime}$ is the resistance measured by the Multimeter, and $\mathrm{W}$ and $\mathrm{D}$ are the width of the sample and the distance between the two copper electrodes, respectively.

\subsection{Tensile test}

Stretching tests were conducted using a Shimadzu EZ mechanical tester. Substrate size was $50 \mathrm{~mm}$ (length) $\times 10 \mathrm{~mm}$ (width). The fabric was elongated / released at a controlled speed of $3.3 \% \mathrm{~s}^{-1}$. The concomitant resistance was measured by an Agilent 34410A digital multimeter during the stretching cycles. 


\subsection{Electrochemical properties of PPy coated fabric}

Cyclic voltammetry and electrochemical impedance spectroscopy were carried out in a standard three-electrode system using a Pt mesh counter electrode, a $\mathrm{Ag} / \mathrm{AgCl}(3 \mathrm{M} \mathrm{NaCl})$ reference electrode, and a PPy coated Nylon Lycra fabric attached onto reticulated vitreous carbon (RVC) as working electrode. The electrolyte was $1.0 \mathrm{M} \mathrm{NaCl}$. Cyclic voltammetry was performed using a Solartron SI 1287 and scanned between $-0.4 \mathrm{~V}$ to $0.5 \mathrm{~V}$. Electrochemical impedance spectra were measured potentiostatically using a PCI4/750 Potentiostat/ Galvanostat/ ZRA (Gamry Instruments, Inc. USA). The frequency range was from $100 \mathrm{kHz}$ to $0.1 \mathrm{~Hz}$ with an $\mathrm{AC}$ perturbation of $10 \mathrm{mV}$ at open circuit potential.

Galvanostatic charge-discharge cycling was carried out in $1.0 \mathrm{M} \mathrm{NaCl}$ using a batterytesting device (Neware Electronic Co., China). PPy coated Nylon Lycra fabric was attached onto RVC and used as electrodes. The cells were charged galvanostatically at $1.0 \mathrm{~A} \mathrm{~g}^{-1}$ to $0.85 \mathrm{~V}$, and then discharged using the same current to a cut-off voltage of $0 \mathrm{~V}$.

\section{Results and discussions}

\subsection{Surface morphology}

The surface morphology of the blank and PPy coated Nylon Lycra fabrics are shown in Fig. 1. After chemical polymerization, PPy was successfully coated on each individual fibre. Some loosely attached aggregates were also observed (Fig. 1b and c). These aggregates could withstand vigorous washing indicative of their strong adherence to the PPy coating layer. The PPy film exhibited a rough surface composed of PPy nodules in different sizes at high magnification (Fig. 1d).

\subsection{Infrared spectroscopy}

Fig. 2 shows the FTIR spectra of uncoated Nylon Lycra fabric and PPy coated fabric. The spectrum of the coated fabric after being stretched for 1000 cycles with $100 \%$ strain 
applied is also shown. The spectrum of uncoated Nylon Lycra demonstrated a stable nylon crystalline structure (Fig. 2 (i)) [25]. Bands at $1640 \mathrm{~cm}^{-1}$ and $1547 \mathrm{~cm}^{-1}$ could be attributed to $\mathrm{C}=\mathrm{O}$ stretching vibrations (Amide I band) and $\mathrm{N}-\mathrm{H}$ bending vibrations (Amide II band) $[26$, 27], respectively. The spectra of the coated fabric before and after stretching were characterized by typical features of PPy $[28,29]$. Those Amide bands attributed to Nylon structure could not be observed, indicating that the fabric fibres were completely coated with a layer of PPy [30]. The band at $1539 \mathrm{~cm}^{-1}$ and $1454 \mathrm{~cm}^{-1}$ corresponded to the C-C and C-N stretching vibrations in the pyrrole ring, respectively. The broad band from 1400 to $1250 \mathrm{~cm}^{-1}$ was attributed to $\mathrm{C}-\mathrm{H}$ or $\mathrm{C}-\mathrm{N}$ in-plane deformation modes and had a maximum at around $1300 \mathrm{~cm}^{-1}$. In the region from 1250 to $1100 \mathrm{~cm}^{-1}$ corresponding to the breathing vibration of the pyrrole ring, the peak was situated at around $1155 \mathrm{~cm}^{-1}$. The peak at $1083 \mathrm{~cm}^{-1}$ was corresponded to the mode of in-plane deformation vibration of $\mathrm{NH}_{2}^{+}$formed on the PPy chains by protonation. The band of $\mathrm{C}-\mathrm{H}$ and $\mathrm{N}-\mathrm{H}$ in plane ring deformation vibration was situated at $1026 \mathrm{~cm}^{-1}$. The peaks at $964 \mathrm{~cm}^{-1}$ and $920 \mathrm{~cm}^{-1}$ could be attributed to C-C out of plane ring deformation vibration and $\mathrm{C}-\mathrm{H}$ out of plane deformation vibration of the ring, respectively [29].

\subsection{Tensile test}

Such PPy coated Nylon Lycra exhibited a surface resistance of $149 \Omega / \square$. The electrical resistance of this conductive fabric was investigated with elongations of $25 \%, 50 \%$ and $100 \%$ applied at a rate of $3.3 \% \mathrm{~s}^{-1}$ at wale direction. Cyclic resistance changes were observed during the mechanical elongation-relaxation process (Fig. 3). The electrical resistance decreased during the elongation process and increased during the relaxation process with $25 \%$ strain applied (Fig. 3a). This could be attributed to the better surfacesurface contacts within yarns on stretching, which made the polymer penetrate into the yarn and improved the conductivity [31]. It is well-recognized that the contact resistance at the 
overlapped points which decreased with loading governed the resistance change of the knitted fabric, for the contacting resistance was much higher than the filament resistance itself [32, 33]. Interestingly, in our work, the electrical resistance appeared in a double-peak phenomenon under the high strain of $50 \%$ and $100 \%$. When the fabric was stretched, the resistance first slightly increased and then decreased forming a peak. This phenomenon also occurred during the strain release process forming the second peak, and it has also been reported by P. Calvert et al. [34]. The formation of this double peak might be attributed to the slow strain recovery of the fabric at large elongation [34], which is consistent with the hysteresis between the elongation and relaxation induced in the strain stress curves (Fig. 3d, 3e and 3f). Higher hysteresis was introduced with higher applied elongation. Our results are different from the previous results reported by $\mathrm{J}$. Wu et al. [22]. In that report the resistance of PPy coated Nylon Lycra fabric decreased significantly at low strains (up to 20\%), followed by slow decrease until a nearly steady state (60\% strain) was attained. These differences might be explained by that PPy used in these two investigations were synthesized under different conditions (e.g., different oxidant, different dopant and different reaction temperature) leading to different electrical properties.

The surface resistance of PPy coated conductive fabric was irreversibly increased after being subjected to elongation-relaxation cycles. Higher irreversible resistance was induced with the higher strain applied. After 1000 cycles of stretching, the resistance was increased by $15 \%, 32 \%$ and $66 \%$ with $25 \%, 50 \%$ and $100 \%$ elongation applied, respectively. This can be explained by the large elongations resulting in severe damage to the PPy film, leading to lower conductivity. Nevertheless, PPy on Nylon Lycra still sustained its conductivity under such high elongation of $100 \%$. It was much higher than $10 \%$, the commonly recognized mechanical strain at which PPy films can endure and still retain their conductivity [35]. This high stretchability might be due to its homogenous distribution as 
nanoparticles on the fabric, which was in agreement with the result obtained with PEDOTPSS on Spandex fabric by Y. Ding et al. [36].

\subsection{Electrochemical properties}

Cyclic voltammetry (CV) was used to determine the electrochemical properties of the PPy coated Nylon Lycra fabric. Fig. 4a shows the CV curves of PPy coated Nylon Lycra fabric attached onto RVC in $1.0 \mathrm{M} \mathrm{NaCl}$ at a scan rate of $10 \mathrm{mV} \mathrm{s}^{-1}$. The blank RVC was also investigated over the same potential range for comparison, and it exhibited a negligible response. PPy exhibited a nearly rectangular $\mathrm{CV}$ behaviour which indicated that the chargedischarge responses of the electric double layer were highly reversible and kinetically facile [37]. However, the rectangular CV shape became distorted when the scan rate reached $25 \mathrm{mV}$ $\mathrm{s}^{-1}$ and above (Fig. 4b). This might be explained by the entering into/ejecting and diffusion of counter ions being too slow compared to the transfer of electrons in the PPy matrix at high scan rates [38].

The specific capacitance of PPy coated Nylon Lycra was calculated using the following equation [39]:

$$
C=\frac{A / 2}{f \times v \times m}
$$

Where $C$ is the specific capacitance, $A$ is the integral area of the cyclic voltammogram loop, $f$ is the scan rate, $v$ is the voltage window, and $\mathrm{m}$ is the mass of electroactive material (PPy). It delivered a specific capacitance of $123.3,100.7,69.7$ and $39.4 \mathrm{~F} \mathrm{~g}^{-1}$ at a scan rate of $10,25,50$ and $100 \mathrm{mV} \mathrm{s}^{-1}$, respectively. PPy coated fabric, after being stretched to $100 \%$ for 1000 cycles, exhibited a much similar electrical response during the cyclic sweeps (not shown). Its specific capacitance slightly decreased by less than $10 \%$ to $113.9,92.9,67.8$ and $38.2 \mathrm{~F} \mathrm{~g}^{-1}$ at scan rates of $10,25,50$ and $100 \mathrm{mV} \mathrm{s}^{-1}$, respectively (Fig. 5). This is further 
proof that this conductive fabric could endure such large mechanical stretching and still sustain its electrical and electrochemical properties.

PPy coated Nylon Lycra fabric was also investigated with in situ strain applied in the electrolyte of $1.0 \mathrm{M} \mathrm{NaCl}$, and the corresponding cyclic voltammograms at a scan rate of 50 $\mathrm{mV} \mathrm{s}^{-1}$ are shown in Fig. 6a. It should be pointed out that the fabric used for this investigation was stretched from its initial or as-synthesized state only, no elongation-relaxation cycle was applied during the measurement. They exhibit a distorted CV shape with no strain applied but with increasing applied strain the electrical response was gradually enhanced; suggestive of promoted electronic transport. A nearly ideal rectangular shaped cyclic voltammogram (CV) was observed when $60 \%$ of strain was applied, indicative of highly reversible and kinetically facile charge-discharge responses of the electric double layer. This might be due to the easy accessibility of ions at the electrolyte-electrode interface and the increased electrical conductivity of PPy coated fabric induced by the applied strain. PPy coated Nylon Lycra was also investigated with strain at a scan rate of $100 \mathrm{mV} \mathrm{s}^{-1}$, and similar phenomenon was observed (not shown). The specific capacitance of PPy coated fabric with different strains applied was calculated and shown in Fig. 6b. The capacitance increased sharply with increasing strain, up to $40 \%$ elongation. It delivered a specific capacitance of 69.7 and $39.4 \mathrm{~F}$ $\mathrm{g}^{-1}$ with $0 \%$ elongation at a scan rate of 50 and $100 \mathrm{mV} \mathrm{s}^{-1}$, respectively. Much higher capacitance of about 101.9 and $88.2 \mathrm{~F} \mathrm{~g}^{-1}$ could be achieved when a $60 \%$ strain was applied. Moreover, only a $28 \%$ capacitance loss was observed when the scan rate reached to $100 \mathrm{mV}$ $\mathrm{s}^{-1}$ from $10 \mathrm{mV} \mathrm{s}^{-1}$ (Fig. 6b inset), compared to $68 \%$ loss with $0 \%$ elongation (Fig. 4b). The capacitance obtained at $50 \mathrm{mV} \mathrm{s}^{-1}$ with $60 \%$ strain applied might be comparable to or lower than that of $235.35 \mathrm{~F} \mathrm{~g} \mathrm{~g}^{-1}$ reported for PPy coated activated carbon at a scan rate of $20 \mathrm{mV} \mathrm{s}^{-1}$ [40]. In their work a conductive stainless steel current collector was used and PPy was electrochemically synthesized. 
Fig. 7 shows the Nyquist plots of PPy coated Nylon Lycra at an equilibrium open circuit potential with or without strain applied. At the high frequency region, the diameter of compressed semicircle afforded the charge-transfer resistance $\left(\mathrm{R}_{\mathrm{ct}}\right)$ in the electrochemical system [41], which decreased with increasing applied strain. The lower electrical impedance was indicative of the improved conductivity. This result was consistent with the improved charge/discharge responses shown in cyclic voltammograms for PPy coated Nylon Lycra.

The charge/discharge profiles of the symmetric supercapacitors composed of PPy coated Nylon Lycra fabrics electrodes at a current density of $1.0 \mathrm{~A} \mathrm{~g} \mathrm{~g}^{-1}$ with different strain applied are presented in Fig. 8. As can be seen, the E-t responses did not follow a linear relationship (Fig. 8a). This might be due to the pseudo-capacitance contributed from the surface-confined Faradaic reaction of PPy. It is also noticed that the duration of one full charge/discharge cycle became longer, indicative of higher capacitance, with increasing strain applied (up to 60\%). These results are consistent with those obtained with $\mathrm{CV}$. The discharge capacitance per electrode can be calculated from the following equation [42]:

$$
C_{m}=\frac{2 Q}{\Delta V \times m}=\frac{2 I \times t}{\Delta V \times m}
$$

Where $C_{\mathrm{m}}, I, t, \Delta V$ and $m$ are the discharge capacitance per electrode, the current of charge-discharge, time of discharge, charge/discharge potential windows and the amount of active materials on one electrode, respectively.

The specific capacitance obtained for PPy coated fabric without strain applied was 108.5 $\mathrm{F} \mathrm{g} \mathrm{g}^{-1}$, with an energy density of $6.7 \mathrm{Wh} \mathrm{kg}^{-1}$ and power density of $753.4 \mathrm{~W} \mathrm{~kg}^{-1}$. The capacitance increased to $117.6,119.6$ and $125.1 \mathrm{~F} \mathrm{~g} \mathrm{~g}^{-1}$ with an elongation of $20 \%, 40 \%$ and $60 \%$, respectively. The corresponding energy density increased to $8.7,9.4$ and $11.1 \mathrm{Wh} \mathrm{kg}^{-1}$, and power density increased to $763.0,765.1$ and $799.2 \mathrm{~W} \mathrm{~kg}^{-1}$ with $20 \%, 40 \%$ and $60 \%$ strain applied, respectively. PPy coated Nylon Lycra fabric with strain applied also exhibited an 
improved cycling stability (Fig. 8b). The capacitance decreased severely to $13.6 \mathrm{~F} \mathrm{~g}^{-1}$ after 500 charge/discharge cycles, only $\sim 12.5 \%$ of the initial capacitance. The retained capacitance was $52.9,63.4$ and $68.8 \mathrm{~F} \mathrm{~g}^{-1}$, about $45 \%, 53 \%$ and $55 \%$ of the initial capacitance with $20 \%$, $40 \%$ and $60 \%$ strain applied, respectively. PPy coated Nylon Lycra fabric delivered a much higher capacitance than stretchable SWCNT integrated into PDMS electrodes $\left(54 \mathrm{~F} \mathrm{~g}^{-1}\right.$ at $1 \mathrm{~A}$ $\left.\mathrm{g}^{-1}\right)$ [7] or fabric electrodes $\left(62 \mathrm{~F} \mathrm{~g}^{-1}\right.$ at $\left.1 \mathrm{~mA} \mathrm{~cm}^{-2}\right)$ [8] but with poorer cycling stability. The capacitance reported here is poorer than PPy coated unwoven ceramic fabrics $\left(208.6 \mathrm{~F} \mathrm{~g}^{-1}\right.$ at $1 \mathrm{~mA} \mathrm{~cm}^{-2}$ ) [43]. The different substrate and different PPy synthesis condition might lead to this difference. It also means that the electrochemical properties of this stretchable PPy coated Lycra electrode can be improved by optimizing or changing the synthesis parameters.

\section{Conclusion}

In this study, we reported the use of a daily-used Nylon Lycra fabric as a platform for stretchable supercapacitor applications. Via chemical polymerization of PPy, a highly conductive textile with a sheet resistance of $149 \Omega / \square$ was produced. Such a conductive fabric showed outstanding flexibility and stretchability, and demonstrated strong adhesion between the PPy and the fabric of interest. This fabric exhibited a nearly rectangular CV behaviour indicative of a capacitor property with a specific capacitance of $123.3 \mathrm{~F} \mathrm{~g} \mathrm{~g}^{-1}$ at a scan rate of $10 \mathrm{mV} \mathrm{s}^{-1}$. During stretching at wale direction, the resistance of this PPy coated Nylon Lycra fabric decreased with increasing elongation. After being stretched for 1000 times, the resistance of this conductive fabric was irreversibly increased. Higher irreversible resistance increase was induced with higher strain applied. Nevertheless, PPy coated Nylon Lycra still sustained its electrochemical properties with less than $10 \%$ specific capacitance loss after being stretched to $100 \%$ for 1000 times. Interestingly, its electrochemical properties could be improved with in-situ strain applied and exhibited a higher specific capacitance. The

capacitance in a three-electrode system increased from 69.7 and $39.4 \mathrm{~F} \mathrm{~g}^{-1}$ with $0 \%$ 
elongation to 101.9 and $88.2 \mathrm{~F} \mathrm{~g}^{-1}$ with $60 \%$ strain applied at a scan rate of 50 and $100 \mathrm{mV} \mathrm{s}^{-1}$, respectively. In a two-electrode system at a current density of $1.0 \mathrm{~A} \mathrm{~g}^{-1}$ the specific capacitance increased from $108.5 \mathrm{~F} \mathrm{~g}^{-1}$ with $0 \%$ strain to $117.6,119.6$ and $125.1 \mathrm{~F} \mathrm{~g}^{-1}$ with $20 \%, 40 \%$ and $60 \%$ elongation, respectively. Also the cycling stability was improved with the applied strain. However, we should point out the cycling stability need to be improved for practical applications. One commonly applied strategy used to overcome this drawback is the formation of composites with carbon-based materials (e.g. carbon nanotubes, graphene etc.). Currently we are working on it.

\section{Acknowledgements}

Financial support from the Australian Research Council is gratefully acknowledged. The authors would also like to thank A/Prof. Chee O. Too for proof-reading of this manuscript. Binbin Yue acknowledges the support of the CSC Scholarship from the Ministry of Education of P.R. China.

\section{References}

[1] S. Coyle, Y. Z. Wu, K. T. Lau, D. De Rossi, G. Wallace, D. Diamond, MRS Bull. 32 (2007) 434 .

[2] B. S. Shim, W. Chen, C. Doty, C. Xu, N.A. Kotov, Nano Lett. 8 (2008) 4151.

[3] F. Carpi, D. De Rossi, IEEE T. Inf. Technol. B 9 (2005) 295.

[4] M. Hamedi, R. Forchheimer, O. Inganäs, Nat. Mater. 6 (2007) 357.

[5] A. Lymberis, A. Dittmar, IEEE Eng. Med. Biol. 26 (2007) 29.

[6] B. E. Conway, Electrochemical supercapacitors : scientific fundamentals and technological applications, Kluwer Academic/Plenum Publisher, New York, 1999. 
[7] C. Yu, C. Masarapu, J. Rong, B. Wei, H. Jiang, Adv. Mater. 21 (2009) 4793.

[8] L. Hu, M. Pasta, F. La Mantia, L. Cui, S. Jeong, H. D. Deshazer, J. W. Choi, S. M. Han, Y. Cui, Nano Lett. 10 (2010) 708.

[9] C. Wang, W. Zheng, Z. Yue, C. O. Too, G. G. Wallace, Adv. Mater. 23 (2011) 3580.

[10] A. Rudge, I. Raistrick, S. Gottesfeld, J. P. Ferraris, Electrochim. Acta 39 (1994) 273.

[11] P. Novák, K. Müller, K. S. V. Santhanam, O. Haas, Chem. Rev. 97 (1997) 207.

[12] H. E. Katz, P. C. Searson, T. O. Poehler, J. Mater. Res. 25 (2010) 1561.

[13] L. Nyholm, G. Nyström, A. Mihranyan, M. Strømme, Adv. Mater. 23 (2011) 3751.

[14] G. A. Snook, P. Kao, A. S. Best, J. Power Sources 196 (2011) 1.

[15] G. Nystrom, A. Razaq, M. Stromme, L. Nyholm, A. Mihranyan, Nano Lett. 9 (2009) 3635 .

[16] M. Jin, G. Y. Han, Y. Z. Chang, H. Zhao, H. Y. Zhang, Electrochim. Acta 56 (2011) 9938.

[17] A. Malinauskas, Polymer 42 (2001) 3957.

[18] G. G. Wallace, T. E. Campbell, P. C. Innis, Fiber. Polym. 8 (2007) 135.

[19] C.Y. Wang, A. M. Ballantyne, S. B. Hall, C. O. Too, D. L. Officer, G. G. Wallace, J. Power Sources 156 (2006) 610.

[20] S. H. Cho, J. S. Joo, B. R. Jung, T. M. Ha, J. Y. Lee, Macromol. Res. 17 (2009) 746.

[21] C. Y. Wang, G. Tsekouras, P. Wagner, S. Gambhir, C. O. Too, D. Officer, G. G. Wallace, Synth. Met. 160 (2010) 76.

[22] J. Wu, D. Zhou, C. O. Too, G. G. Wallace, Synth. Met. 155 (2005) 698.

[23] A. Varesano, A. Aluigi, L. Florio, R. Fabris, Synth. Met. 159 (2009) 1082.

[24] F. Ferrero, L. Napoli, C. Tonin, A. Varesano, J. Appl. Polym. Sci. 102 (2006) 4121.

[25] C. F. Xiao, X. M. Tao, S. M. Y. Leung, K.W.Y. Kwok, Polym. Int. 55 (2006) 101. 
[26] M. Afshari, A. Gupta, D. Jung, R. Kotek, A. E. Tonelli, N. Vasanthan, Polymer 49 (2008) 1297.

[27] C. H. Do, E. M. Pearce, B. J. Bulkin, H. K. Reimschuessel, J. Polym. Sci., Part A: Polym. Chem. 25 (1987) 2409.

[28] J. Liu, M. Wan, J. Mater. Chem. 11 (2001) 404.

[29] M. Omastová, M. Trchová, J. Kovářová, J. Stejskal, Synth. Met. 138 (2003) 447.

[30] A. Varesano, B. Antognozzi, C. Tonin, Synth. Met. 160 (2010) 1683.

[31] H. Zhang, X. Tao, T. Yu, S. Wang, X. Cheng, Meas. Sci. Technol. 17 (2006) 450.

[32] H. Zhang, X. M. Tao, S. Y. Wang, T. X. Yu, Text. Res. J. 75 (2005) 598.

[33] X. Tao, Textile Institute., Ebrary., Wearable electronics and photonics, Woodhead ; CRC Press, Cambridge Boca Raton FL, 2005.

[34] P. Calvert, D. Duggal, P. Patra, A. Agrawal, A. Sawhney, Mol. Cryst. Liq. Cryst. 484 (2008) 291/[657].

[35] H. H. Kuhn, A. D. Child, W.C. Kimbrell, Synth. Met. 71 (1995) 2139.

[36] Y. Ding, M. A. Invernale, G. A. Sotzing, ACS Appl. Mater. Inter. 2 (2010) 1588.

[37] S. R. S. Prabaharan, R. Vimala, Z. Zainal, J. Power Sources 161 (2006) 730.

[38] J. P. Wang, Y. L. Xu, J. Wang, X. F. Du, F. Xiao, J. B. Li, Synth. Met. 160 (2010) 1826.

[39] X. Li, J. Rong, B. Wei, ACS Nano 4 (2010) 6039.

[40] B. Muthulakshmi, D. Kalpana, S. Pitchumani, N. G. Renganathan, J. Power Sources 158 (2006) 1533.

[41] K. Wang, J. Y. Huang, Z. X. Wei, J. Phys. Chem. C 114 (2010) 8062.

[42] Q. F. Wu, K. X. He, H. Y. Mi, X. G. Zhang, Mater. Chem. Phys. 101 (2007) 367.

[43] H. Lee, H. Kim, M. S. Cho, J. Choi, Y. Lee, Electrochim. Acta 56 (2011) 7460. 


\section{Captions}

Fig. 1 FESEM images of (a) blank and (b, c and d) PPy coated Nylon Lycra fabric.

Fig. 2 FTIR spectra of blank Nylon Lycra fabric (i), as-synthesized PPy coated Nylon Lycra fabric (ii), and PPy coated Nylon Lycra fabric after being stretched to $100 \%$ for 1000 times at wale direction (iii).

Fig. 3 ( $a, b$ and c) Normalized electrical resistances under cyclic elongations and (d, e and f) strain-force curves for PPy coated Nylon Lycra fabric at wale direction with different strains applied. Strain applied was (a, d) 25\%, (b, e) 50\% and (c, f) $100 \%$.

Fig. 4 (a) Cyclic voltammograms of blank RVC (i), and PPy coated Nylon Lycra fabric attached onto $\mathrm{RVC}$ in $1.0 \mathrm{M} \mathrm{NaCl}$ at a scan rate of $10 \mathrm{mV} \mathrm{s}^{-1}$ (ii). (b) Cyclic voltammograms of PPy coated Nylon Lycra fabric attached onto RVC in $1.0 \mathrm{M} \mathrm{NaCl}$ at different scan rates: 10 (i), 25 (ii), 50 (iii) and $100 \mathrm{mV} \mathrm{s}^{-1}$ (iv).

Fig. 5 The specific capacitance of the as-synthesized PPy coated fabric (i), and the fabric after being stretched to $100 \%$ for 1000 times (ii) at different scan rates.

Fig. 6 (a) Cyclic voltammograms of PPy coated Nylon Lycra fabric with different strains applied at a scan rate of $50 \mathrm{mV} \mathrm{s}^{-1}$ in $1.0 \mathrm{M} \mathrm{NaCl}: 0 \%$ (i), $20 \%$ (ii), $40 \%$ (iii) and $60 \%$ (iv). (b) Specific capacitance of PPy coated Nylon Lycra fabric obtained at a scan rate of $50 \mathrm{mV} \mathrm{s}^{-1}$ and $100 \mathrm{mV} \mathrm{s}^{-1}$ with different strains applied. Inset: cyclic voltammograms of PPy coated fabric with $60 \%$ elongation applied in $1.0 \mathrm{M} \mathrm{NaCl}$ at different scan rates: 10 (i), 25 (ii), 50 (iii) and $100 \mathrm{mV} \mathrm{s}^{-1}$ (iv).

Fig. 7 Nyquist plots of PPy coated Nylon Lycra fabric in $1.0 \mathrm{M} \mathrm{NaCl}$ with different strains applied.

Fig. 8 (a) Charge/discharge curves of PPy coated fabric with different applied strain: (i) $0 \%$, (ii) $20 \%$, (iii) $40 \%$ and (iv) $60 \%$ at a current density of $1.0 \mathrm{~A} \mathrm{~g}^{-1}$. (b) Discharge capacitance 
versus cycle number at $1.0 \mathrm{~A} \mathrm{~g}^{-1}$ for PPy coated fabric with different strain applied: (i) $0 \%$, (ii) $20 \%$, (iii) $40 \%$ and (iv) $60 \%$.
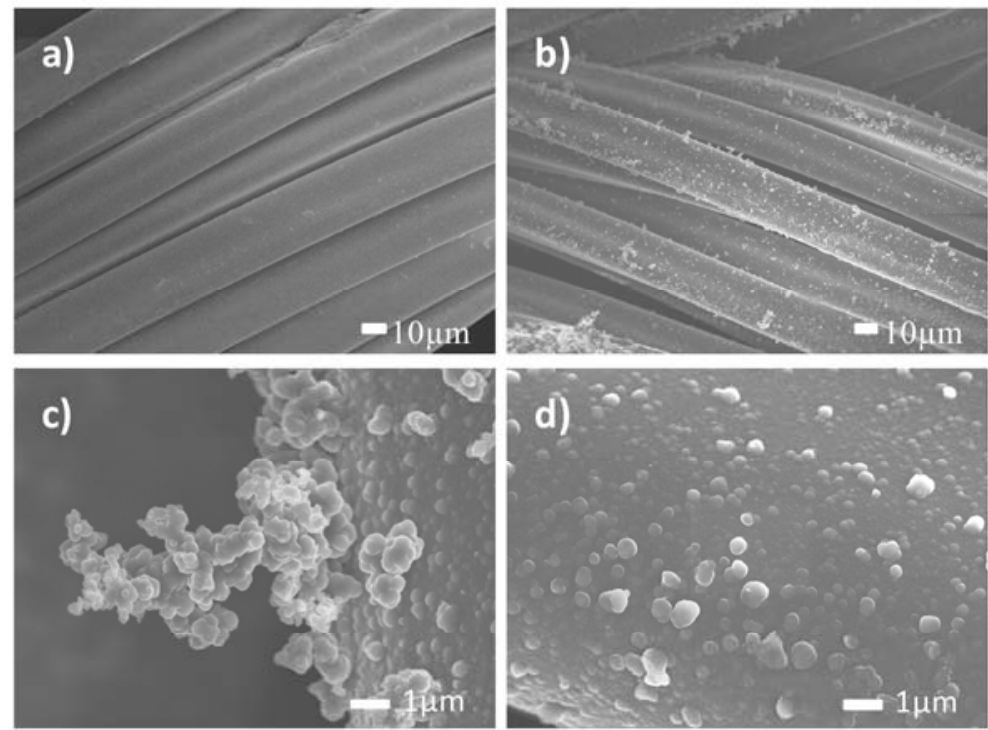

Figure 1 


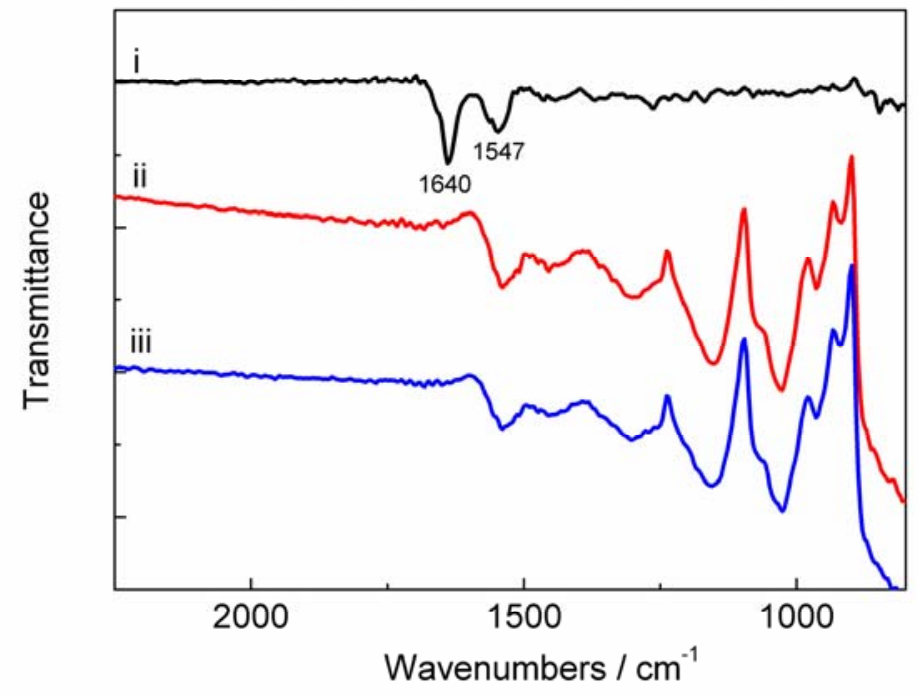

Figure 2 

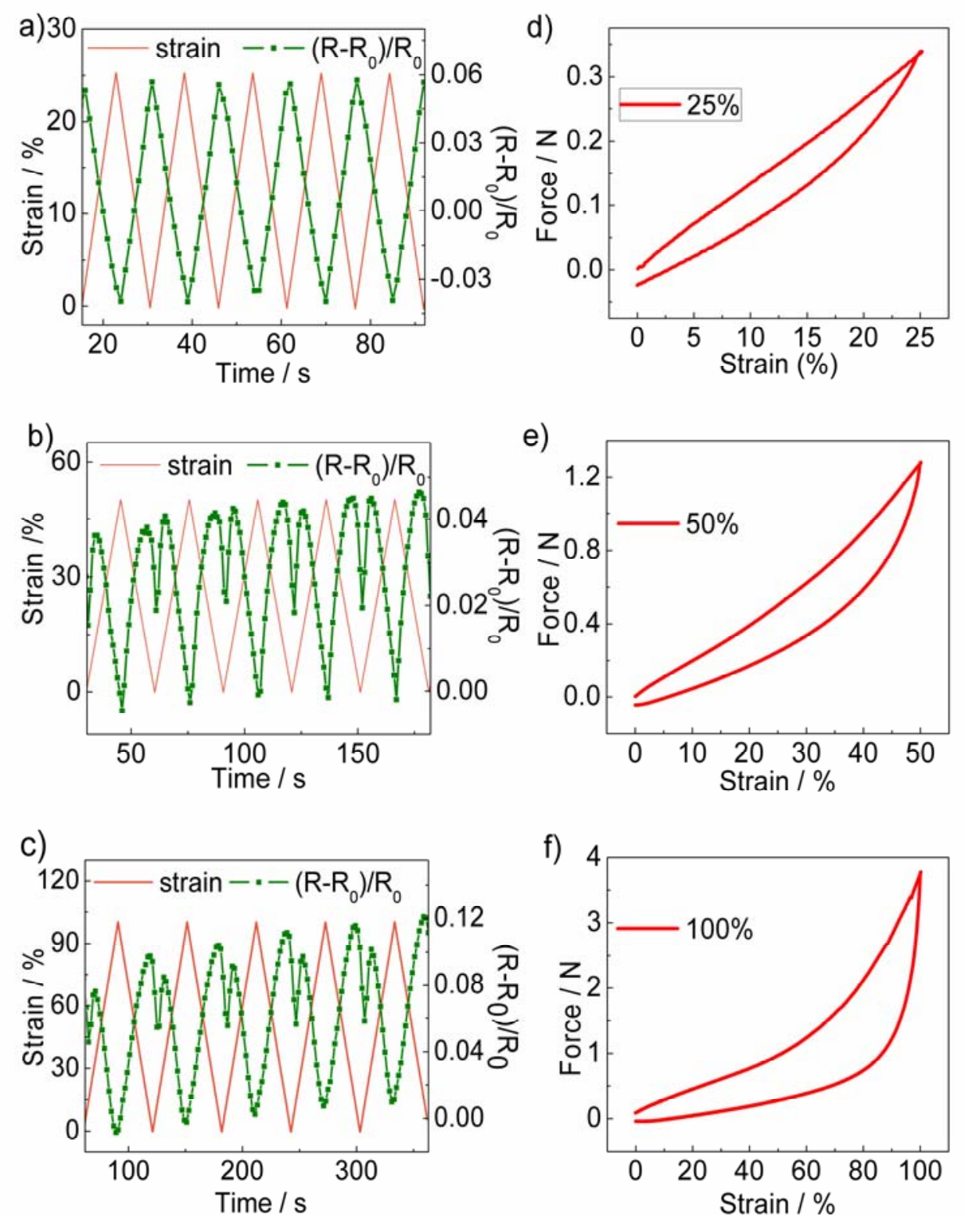

Figure 3 
a)
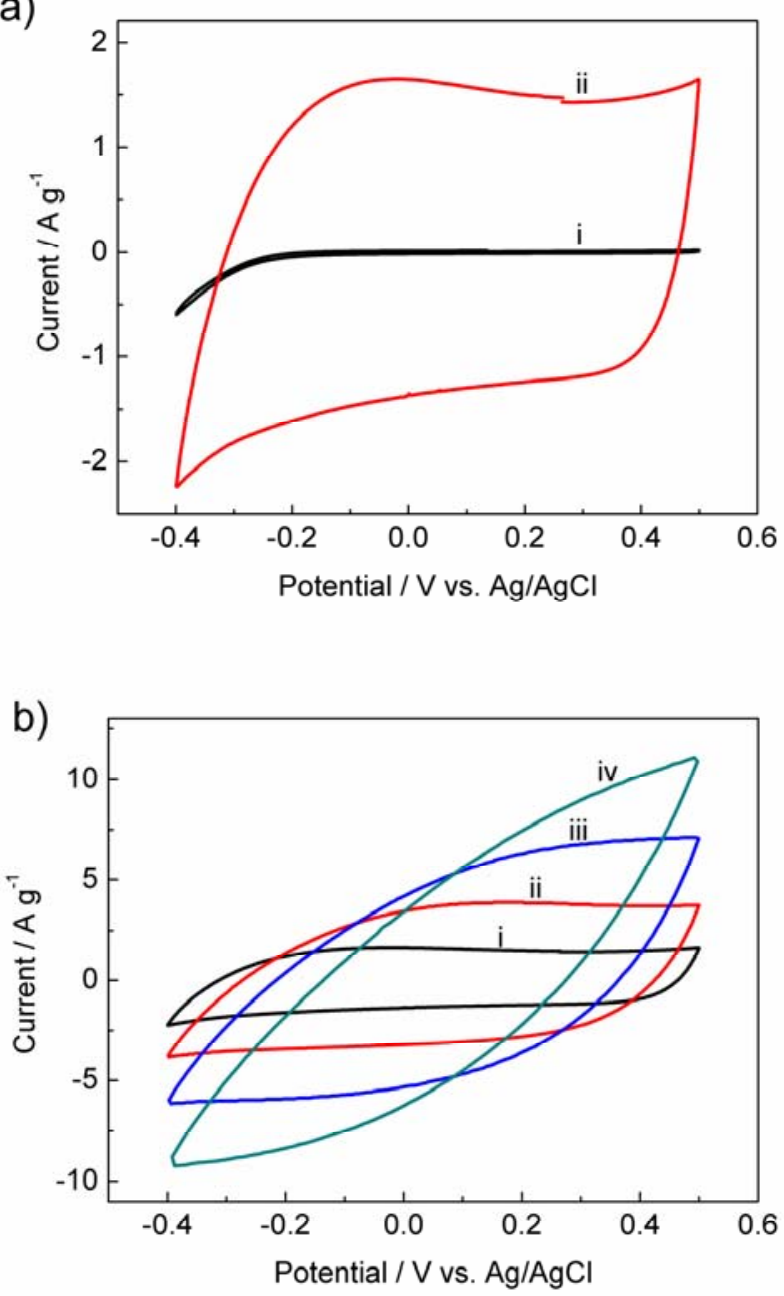

Figure 4 


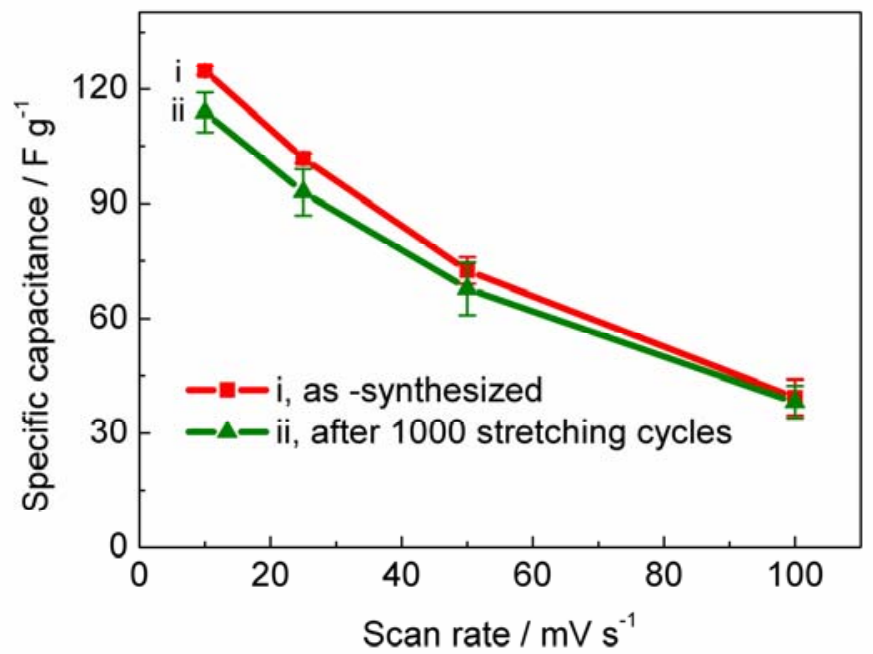

Figure 5 

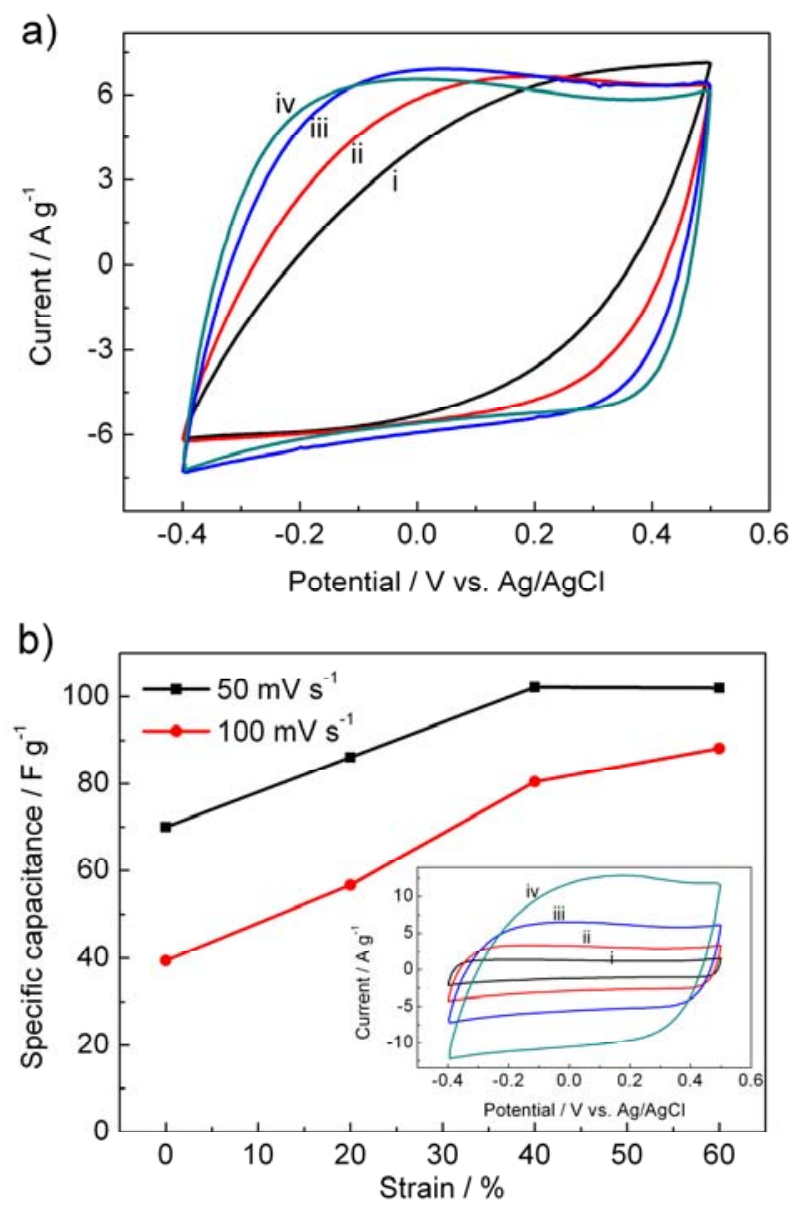

Figure 6 


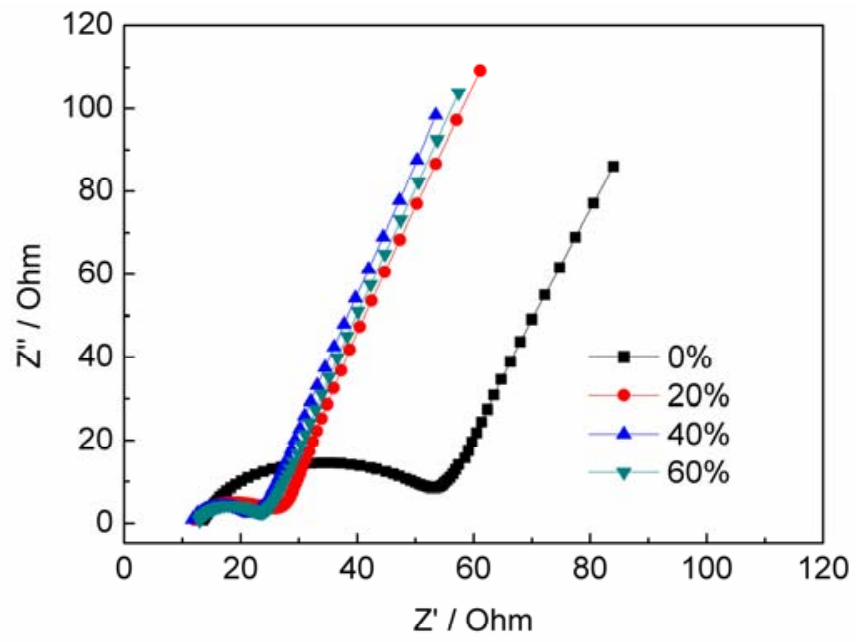

Figure 7 

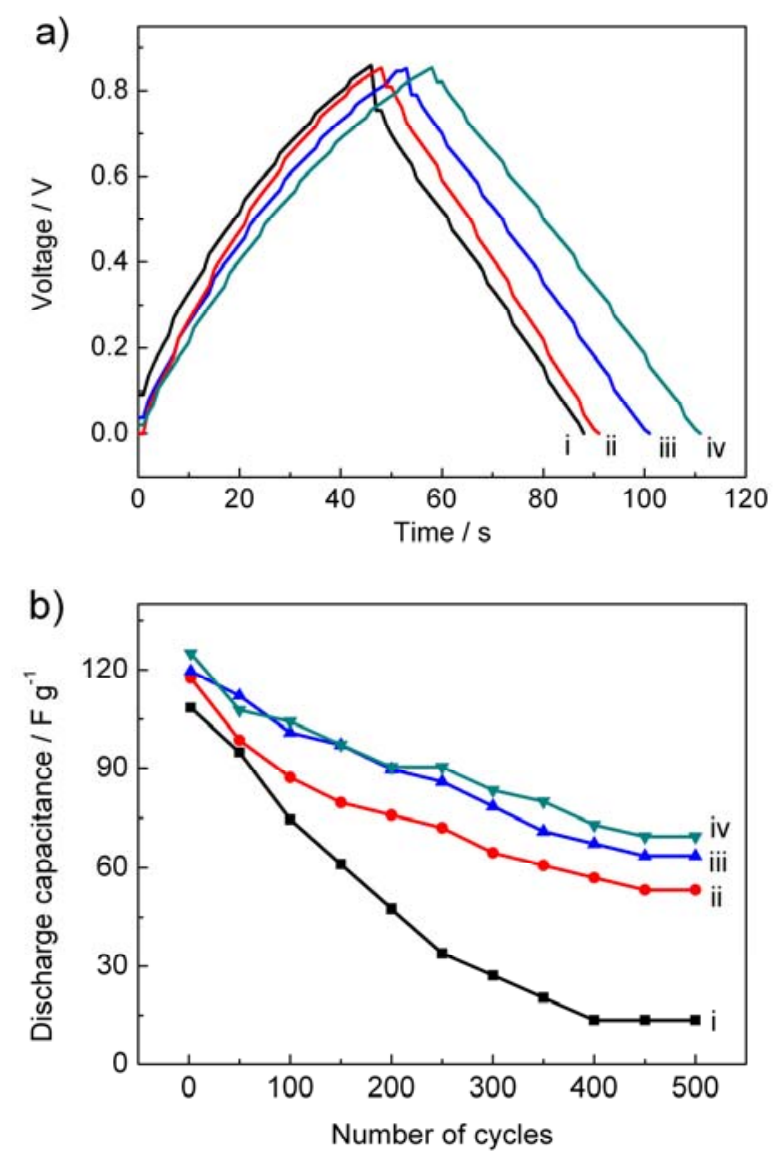

Figure 8 